\title{
BARNARD, Julienne, Mémoires Chapais - Tome I - \\ Documentation - Correspondances - Souvenirs 1744-1848. Fides, Montréal et Paris, 1961. Préface d'Émile Chartier, p.d. Page liminaire, Remerciements de J. B. (Julienne Barnard), Appendice, Index, Table des matières, 305 p.
}

\section{Lionel Groulx}

Volume 15, numéro 2, septembre 1961

URI : https://id.erudit.org/iderudit/302124ar

DOI : https://doi.org/10.7202/302124ar

Aller au sommaire du numéro

Éditeur(s)

Institut d'histoire de l'Amérique française

ISSN

0035-2357 (imprimé)

1492-1383 (numérique)

Découvrir la revue

Citer ce compte rendu

Groulx, L. (1961). Compte rendu de [BARNARD, Julienne, Mémoires Chapais Tome I - Documentation - Correspondances - Souvenirs 1744-1848. Fides, Montréal et Paris, 1961. Préface d’Émile Chartier, p.d. Page liminaire,

Remerciements de J. B. (Julienne Barnard), Appendice, Index, Table des matières, 305 p.] Revue d'histoire de l'Amérique française, 15(2), 306-307. https://doi.org/10.7202/302124ar d'utilisation que vous pouvez consulter en ligne. 
Barnard, Julienne, Mémoires Chapais - Tome I - Documentation - Correspondances - Souvenirs 1744-1848. Fides, Montréal et Paris, 1961. Préface d'Emile Chartier, p.d. 
Page liminaire, Remerciements de J. B. (Julienne Barnard), Appendice, Index, Table des matières, 305 pages.

Nous n'essaierons pas de résumer ce premier volume des Mémoires Chapais. Il nous faudrait dépasser de beaucoup les limites ordinaires d'un compte rendu. Qu'il suffise, pour en marquer l'importance, de citer quelques lignes du préfacier, Mgr Emile Chartier, p.d.: "Le cadre où évoluent ces acteurs de premier plan [qui figurent dans cet ouvrage] ne saurait laisser personne indifférent . . . La vie tumultueuse que connurent alors ces seigneuries [de la Bouteillerie et de Saint-Denis] offre une synthèse assez exacte de l'existence troublée qui fut en ce temps celle de tout le pays. » On nous annonce en préparation deux autres tomes, l'un qui couvrira la période de 1848-1879, l'autre, celle de 1880-1888. Le tome II devrait nous apporter, espérons-le, un témoignage de premier ordre, celui d'un témoin et acteur de la dernière période de l'Union des Canadas et de la célèbre «Conférence » de Québec qui a élaboré le projet de Confédération canadienne. Il va de soi, néanmoins, quel que soit l'intérêt de ce premier tome, que nous attendons surtout les Mémoires de M. Thomas Chapais. L'homme fut sûrement l'une des figures marquantes de son époque. Il était d'un esprit élevé et de vraie noblesse. Les historiens ne peuvent oublier qu'avant l'introduction de l'Histoire canadienne dans les universités du Québec, Thomas Chapais fut, avec Joseph-Edmond Roy, l'auteur de l'Histoire de la seigneurie de Lauzon, le plus remarquable ouvrier de notre historiographie, avec son Intendant Talon et son Marquis de Montcalm. 